\title{
Gene diversity and identification of putative hybridizing parents for root rot resistance in cassava using simple sequence repeats
}

\author{
Oluwasayo Kehinde Moyib ${ }^{1,2,3 *}$, Jonathan Mkumbira ${ }^{2}$, Oyeronke Adunni Odunola $^{3}$ and \\ Alfred Godwin Dixon ${ }^{2,4}$
}

\footnotetext{
${ }^{1}$ Department of Petroleum and Chemical Sciences, Tai Solarin University of Education, Lagos-Benin Express Road, P. M. B. 2118, ljebu-Ode, Ogun State, Nigeria.

${ }^{2}$ Cassava Breeding Unit, International Institute of Tropical Agriculture (IITA) P. M. B. 5320, Oyo Road, Ibadan, Oyo State, Nigeria.

${ }^{3}$ Department of Biochemistry, University of Ibadan, Ibadan, Oyo State, Nigeria.

${ }^{4}$ Sierra Leone Agricultural Research Institute, Tower Hill, P. M. B. 1313 Freetown, Sierra Leone.
}

\section{Accepted 30 July, 2012}

\begin{abstract}
The incidence of root rot diseases partly contribute to the currently observed low percentage increase in the yield of cassava. We estimated gene diversities and identified putative hybridizing parents for root rot resistance using 18 simple sequence repeats loci in $\mathbf{4 3}$ improved genotypes of cassava. Root rot was measured over 2 years as the percentage proportion of rotten roots to the total number of roots harvested at 12 month after planting. Estimated rot ranged from 1.2 to $21.2 \%$ with a mean of $5.7 \pm 0.5$. Rank-sum analysis generated 8 rot classes and identified TMS 96/1089A as best genotype resistant to root rot. Gene diversity analysis revealed expected heterozygosity that ranged from 0.701 for very highly susceptible genotypes to $\mathbf{0 . 7 8 1}$ for moderately resistant and susceptible. Genetic differentiation ranged from -0.0178 (resistant and susceptible) to 0.0523 (very highly resistant and highly resistant genotypes). A total heterozygosity of 0.764 was estimated and was largely due to within class diversity (0.755). DNA analysis representatives for window (DARwin) identified 10 hybridizing groups with a dissimilarity coefficient that ranged from 0.18 to 0.81 on a mean of 0.60 . The results obtained from the present study are useful for the genetic improvement of cassava against root rot disease.
\end{abstract}

Key words: Cassava genotypes, gene diversity, heterozygosity, resistant genotypes, root rot disease.

\section{INTRODUCTION}

Cassava, Manihot esculenta Crantz, is the main starchy staple of the lowland tropics that has recently gained global popularity because of its combined food, feed, fiber, and bio-fuel traits. It is therefore targeted for the reduction of food insecurity and poverty in Africa. Cassava production in Africa increased tremendously from 81.2 million tonnes in 1995 to 117.449 million

*Corresponding author. E-mail: kmoyib@hotmail.com or okmoyib@gmail.com. Tel: +234818 8464072. tonnes in 2006 (FAO, 1995, 2006). This increased production could be attributed to the adoption of improved cultivars developed in International Institute of Tropical Agriculture (IITA) Ibadan combined with the introduction of good farming practices to the farmers. However, cassava production in Africa has little increased in recent years over what it was in 2006 to an estimate of 126.627 million tonnes in 2010 (FAO, 20062010). The currently observed stagnation in production might be attributed partly to stresses such as postharvest deterioration (physiologic or pathogenic) and disease (mosaic disease, bacterial blight, anthracnose, and more 
recently root rot) prevalent in the producing regions.

Cassava root rot is becoming a very important disease of cassava and was first discovered in West Africa by Mskita et al. (1998). It was reported to cause about 20 to $80 \%$ yield loss (Mskita et al., 2005). Aigbe and Remison (2010) reported that the starch content and quality of garri decreased with increasing incidence or severity of root rot among assessed varieties of cassava. Reported causes of cassava root rot diseases are water logged or flooded soils and microorganisms (fungi and bacteria) that are hydrophilic.

Lately, a large parasitic mushroom (Polyporus sulphureus) has been found to be causing severe root rot of cassava in some parts of Ghana and is capable of causing $100 \%$ yield loss in susceptible cultivars (Moses et al., 2005). Commonly reported symptoms associated with cassava root rot are brown and wilting plants defoliation, shoot or stem dieback. The major observation is at the harvest: the roots are swollen, soft, give out an offensive odour and often discoloured when cut. The use of resistant or tolerant cultivars has been listed among the measures to control cassava root rot (Moses et al., 2005). Therefore, efforts are geared towards evaluating and screening cassava germplasm for root rot to identify resistant or tolerant varieties (Onyeka et al., 2006; Okechukwu et al., 2009) that can be used as parents for the crop's genetic improvement.

Molecular marker biotechnology has proven useful and substantial in complementing conventional breeding over the years, especially for disease resistance and high yield in cassava (Fregene and Puonti-Kaerlas, 2005). Genomic tools such as genetic diversity studies either in revealing the genetic relatedness for broadening gene pools, genotype identification, or the elimination of redundancy/duplicates are crucial for any breeding objective in cassava genetic improvement. Molecular markers that are polymerase chain reaction-based are routinely used for genetic diversity studies in crops (Tautz, 1989; Williams et al., 1990). Simple sequence repeat markers (SSR) are preferred in cassava genomics because of their co-dominancy, reproducibility, and unambiguous data, and also, they are cheap and easy to use. SSR markers have been used over the years for genomics analyses in cassava which ranged from dissecting genetic relatedness, and molecular mapping, to marker-assisted selection (Mba et al., 2001; Fregene at al., 2003; Okogbenin et al., 2006; Moyib et al., 2007; Siqueira et al., 2009).

We, therefore, sought to employ SSR markers to evaluate the gene diversity parameters such as heterozygosity and genetic differentiation and also to identify putative parents with which hybridization and introgression of useful genes for root rot resistance is possible among the improved genotypes of cassava that are bred for disease resistances. This study is expected to enhance the molecular breeding of a large number of new cassava varieties that are resistant or tolerant to root rot diseases. Therefore, the study offers measurable benefits in improving the livelihood of cassava farmers in rural areas and also increasing cassava productivity in Africa.

\section{MATERIALS AND METHODS}

\section{Plant materials}

This study was conducted in 2004/2005, 2005/2006 and 2006/2007 at the research farm of IITA-Ibadan, Nigeria with an average annual rainfall of $1305 \mathrm{~mm}$; an altitude of $243 \mathrm{~m}$; mean annual temperature of 20 to $34^{\circ} \mathrm{C}$; coordinates $7^{\circ} 31^{\prime} \mathrm{N}$; $3^{\circ} 54^{\prime} \mathrm{E}$; and ferric luvisol soil. The 43 improved genotypes of cassava developed at IITA for disease resistance and high yielding were used. The experimental design was a randomized complete block in four replications under rain-fed conditions. Mature stem cuttings of $0.25 \mathrm{~m}$ long of 43 genotypes were planted on plots of six ridges at a spacing of $1 \mathrm{~m}$ between ridges and $1 \mathrm{~m}$ within ridges. A ridge was $6 \mathrm{~m}$ long and 0.3 $\mathrm{m}$ wide, so each plot contained 36 plants. Pre-emergence herbicide as recommended ( $1 \%$ gramozone at $4 \mathrm{~L} / \mathrm{ha}$ ) and hand weeding were used to control weeds.

\section{Evaluation of root rot disease}

Data on root rot diseases were collected from 4 inner ridges on 36 plants at 12 month after planting (MAP). Root rot was measured as the percentage proportion of rotten roots to the total number of roots harvested that is, Rootrot $=\left(N R_{t} R s / T N R s\right) * 100$ (where Root rot $=$ Rootrot, $N R_{t} R s=$ Number of rotten roots, TNRs $=$ Total number of roots harvested). The estimated data for root rot diseases were analyzed for precision measures using Statistical system of analysis software (SAS, 2002).

\section{Grouping of genotypes into root rot resistant classes}

Rank-sum procedure in SAS was used to group the 43 genotypes into different phenotypic classes for root rot resistance. Rank-sum first assigned rank $($ rank $=X n)$ to the genotypes in descending order based on their estimated mean rot. Grand mean $(G n=$, the deviation $(D=G n-X n)$, standard deviation $(S D=\sqrt{X n / N)}$, and standardized mean (stdzdmean $=D / S D$ ) were calculated for the ranking. The estimated stzdmean is then used to generate the classes among the genotypes using the following synthax as used in the rank-sum procedure: If the standardized mean is $<=-3$, then the class is 'very highly resistant' (VHR); otherwise, if it is $<-3$ but $<=-2$, the class is 'highly resistant' $(H R)$; if it is $<-2$ but $<=-1$, the class is 'resistant' (R); if it is $<-1$ but $<0$ ' it is 'moderately resistant' (MR); if it is <= 0 but $<1$, then it is 'moderately susceptible' (MS); if it is $<=1$ but $<2$, then the class is 'susceptible' (S); if it is $<=2$ but $<3$, it is 'highly susceptible' (HS). If the standardized mean is $>=3$, the class is 'very highly susceptible' (VHS).

\section{SSR analysis}

Genomic DNA was isolated using modified Dellaporta et al. (1983) for DNA mini-preparation. Eighteen SSR markers were used to amplify genomic DNA from the 43 genotypes of cassava evaluated for rot resistance. The amplified products were separated on $6 \%$ polyacrylamide gel electrophoresis using silver staining for visualization. The DNA bands were scored as 1 for the presence of 


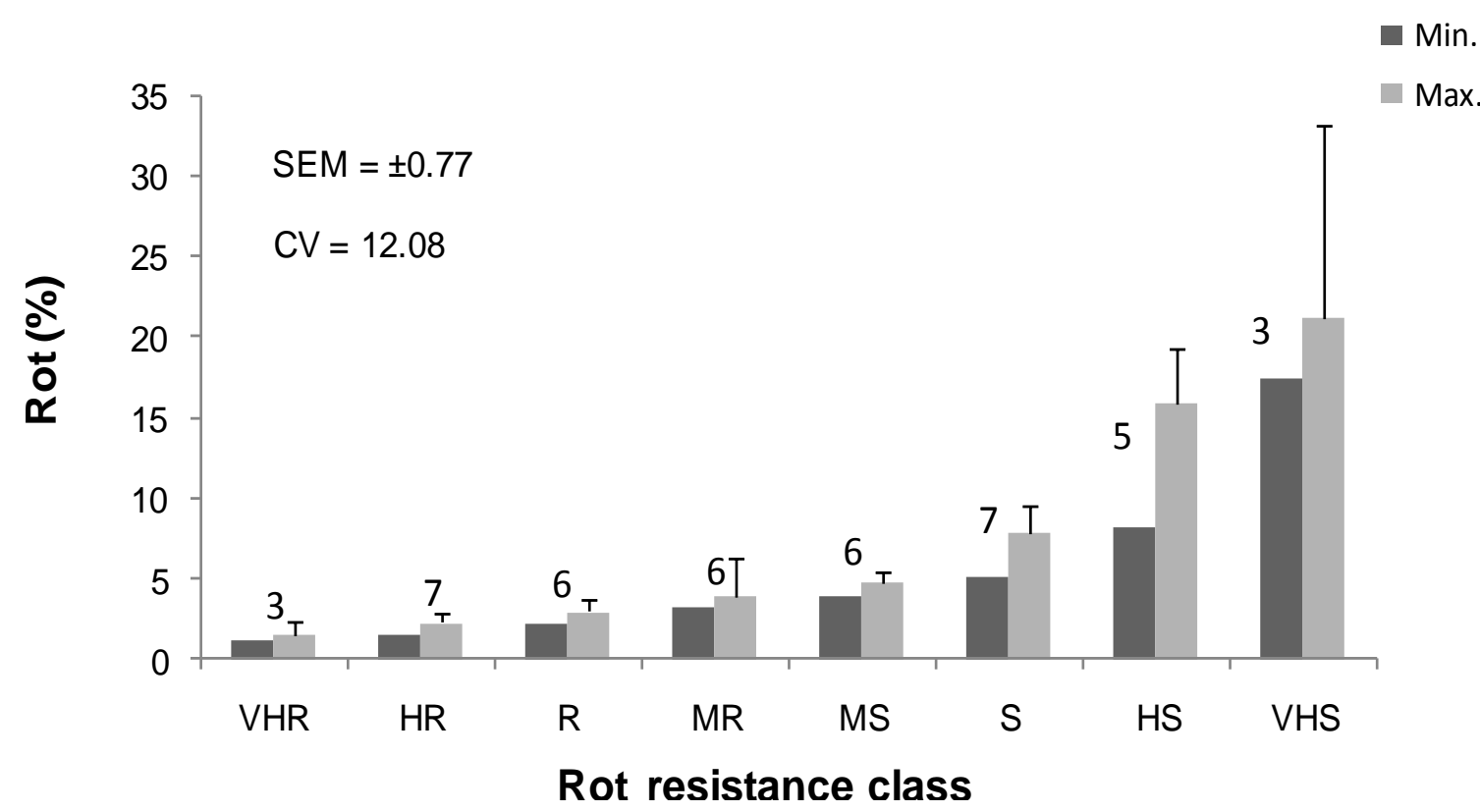

Figure 1. Variation of estimated minimum and maximum values of root rot and number of genotypes within each of the eight root rot resistance classes among the $43 \mathrm{CMD}$-resistant genotypes of cassava assessed. VHR, very highly resistant; HR, highly resistant; $R$, resistant; MR, moderately resistant; MS, moderately susceptible; S, susceptible; HS, highly susceptible; VHS, very highly susceptible. The genotypes were distributed into eight different classes of rot resistance based on the rank sum analysis in SAS. Min. and max. values within each class is shown at the center of data points. The number of genotypes in each class is given directly outside the dat a point of each class.

a DNA band and 0 for the absence of a DNA band. The raw single data was transformed into bi-allelic data and analyzed using Fstatistics (FSTAT) version 2.9.3.2 software package (Goudet, 2002) for F-statistics such as mean number of alleles $(\hat{A})$, mean allelic richness (Â.R), and percentage of polymorphic loci (P\%) and also for gene diversity estimators, heterozygosity $(\mathrm{He})$ such as expected heterosygosity $\left(\hat{H}_{\mathrm{e}}\right)$, observed heterozygosity $\left(\mathrm{H}_{\mathrm{O}}\right)$, within class heterozygosity $\left(\mathrm{H}_{\mathrm{S}}\right)$, among class heterozygosity $\left(\mathrm{D}_{\mathrm{ST}}\right)$, total heterozygosity $\left(\mathrm{H}_{\mathrm{T}}\right)$, and proportion of among class heterozygosity (Gst) according to Nei (1978) and genetic differentiation based on fixation index ( $F_{S T}$, theta) estimation over allele, locus and population as described by Weir and Cockerham (1984). Pairwise values of $F_{\mathrm{ST}}$ between rot classes were also estimated and the matrix was analyzed by cluster analysis using unweighted pairgroup method of arithmetic in numeric taxonomy system of statistics (NTSYS) software package (Roulph, 2000). The single molecular data of SSR markers and the rank-sum of the genotypes were subjected to cluster analysis for the identification of genotypic groups with which easy hybridization is possible so as to generate large number of new varieties with possible root rot resistance among the genotypes using DARwin software package (Perrier and Jacquemoud-Collet, 2006).

\section{RESULTS}

\section{Variation and ranking of rot among cassava genotypes}

The harvested TNRs ranged from 5.00 - 139.00 with a mean of $63.36 \pm 1.33$ and $N_{\mathrm{t}} \mathrm{Rs}$ ranged from 0 - 16 with a mean of 2.72 \pm 0.18 . The mean TNRs and $N R_{t} R s$ at 12
MAP varied very highly significantly among the 43 genotypes of cassava studied $(\mathrm{CV}=135.4)$. The estimated rot ranged from 0.0 to $90.9 \%$ with a mean of $5.7 \pm 0.5 \%$. The estimated mean rot among genotypes ranged from $1.2 \pm 1.0 \%$ for TMS $96 / 1089 \mathrm{~A}$ to $21.2 \pm 12.0 \%$ for TMS 92/0067 with an average of $5.71 \pm 0.48 \%$. Based on the rank-sum procedure used, 8 classes of rot resistance were generated among the 43 genotypes with 3 genotypes, each, in VHR and VHS class and there were $7 \mathrm{HR}, 6 \mathrm{H}, 6 \mathrm{MR}, 6 \mathrm{MS}, 7 \mathrm{~S}$, and $5 \mathrm{HS}$, among the 43 genotypes (Figure 1). The 3 genotypes in the VHR were TMS 96/1089A (mean rot of $1.2 \pm 1.0 \%, 97 / 4779$ $(1.4 \pm 0.7 \%)$, and $94 / 0561(1.5 \pm 0.8 \%)$ and were identified as the best three genotypes for rot resistance; and VHS genotypes were TMS 99/6012 (17.5 \pm 12.4$)$, 94/0026 (19.1 \pm 6.5$)$, and 92/0067 (21.2 $\pm 12.0 \%)$. The descriptive statistics and rank-sum analysis for the classes of rot among the 43 genotypes are given in Table 1.

\section{Gene diversity and identification of putative hybridizing parents for root rot resistance}

A total number of 102 alleles were amplified from the genome of the 43 improved genotypes of cassava using 18 SSR loci, the profile pattern among the 43 cassava clones by SSRY101 is shown in Figure 2. F-statistics analysis results for rot classes showed an estimated Ạ 
Table 1. Mean rot, standard deviation, standard error, coefficient of variation, range, minimum, maximum, ranking, standardized mean, and class for root rot resistance in 43 CMD-resistant genotypes of assessed rot at IITA-lbadan in 2005 and 2006.

\begin{tabular}{|c|c|c|c|c|c|c|c|c|c|c|c|c|}
\hline \multirow{2}{*}{$\mathbf{S} / \mathbf{N}$} & \multirow{2}{*}{ Genotype } & \multirow{2}{*}{$\begin{array}{l}\text { Mean } \\
\text { rot \% } \\
\end{array}$} & \multicolumn{6}{|c|}{ Descriptive measures } & \multicolumn{4}{|c|}{ Rank-sum Analysis $\dagger$} \\
\hline & & & SD & SE \pm & $\mathrm{CV}$ & Range & Min. & Max. & $\mathbf{X n}$ & D & stdmean & Class \\
\hline 1 & $96 / 1089 \mathrm{~A}$ & 1.2 & 2.4 & 1.0 & 199.2 & 5.9 & 0.0 & 5.9 & 43 & -21 & -3.4 & VHR \\
\hline 2 & $97 / 4779$ & 1.4 & 2.0 & 0.7 & 143.9 & 6.0 & 0.0 & 6.0 & 42 & -20 & -3.2 & VHR \\
\hline 3 & $94 / 0561$ & 1.5 & 2.1 & 0.8 & 137.7 & 5.0 & 0.0 & 5.0 & 41 & -19 & -3 & VHR \\
\hline 4 & TME419 & 1.6 & 2.6 & 1.1 & 160.8 & 5.9 & 0.0 & 5.9 & 40 & -18 & -2.8 & $\mathrm{HR}$ \\
\hline 5 & $95 / 0289$ & 1.7 & 1.0 & 0.4 & 59.6 & 2.8 & 0.0 & 2.8 & 39 & -17 & -2.8 & $\mathrm{HR}$ \\
\hline 6 & 99/3073 & 1.7 & 2.6 & 0.9 & 153.8 & 7.0 & 0.0 & 7.0 & 38 & -16 & -2.6 & $\mathrm{HR}$ \\
\hline 7 & $92 / 0057$ & 2.0 & 1.9 & 0.7 & 95.8 & 5.4 & 0.0 & 5.4 & 37 & -15 & -2.4 & $\mathrm{HR}$ \\
\hline 8 & $94 / 0039$ & 2.1 & 3.2 & 1.6 & 147.8 & 6.7 & 0.0 & 6.7 & 36 & -14 & -2.2 & $\mathrm{HR}$ \\
\hline 9 & $97 / 4769$ & 2.2 & 1.2 & 0.5 & 57.4 & 3.5 & 0.0 & 3.5 & 35 & -13 & -2 & $\mathrm{HR}$ \\
\hline 10 & $91 / 02324$ & 2.3 & 1.2 & 0.5 & 54.1 & 3.4 & 0.0 & 3.4 & 34 & -12 & -2 & $\mathrm{HR}$ \\
\hline 11 & $97 / 2205$ & 2.3 & 3.7 & 1.5 & 161.8 & 9.4 & 0.0 & 9.4 & 33 & -11 & -1.8 & $\mathrm{R}$ \\
\hline 12 & $96 / 1565$ & 2.5 & 1.7 & 0.9 & 68.7 & 3.7 & 0.0 & 3.7 & 32 & -10 & -1.6 & $\mathrm{R}$ \\
\hline 13 & $97 / 3200$ & 2.5 & 3.9 & 1.6 & 153.9 & 10.0 & 0.0 & 10.0 & 31 & -9 & -1.4 & $\mathrm{R}$ \\
\hline 14 & $95 / 0379$ & 2.8 & 2.9 & 1.2 & 101.1 & 7.0 & 0.0 & 7.0 & 30 & -8 & -1.2 & $\mathrm{R}$ \\
\hline 15 & $97 / 4763$ & 2.8 & 0.8 & 0.3 & 27.2 & 2.1 & 2.2 & 4.3 & 29 & -7 & -1.2 & $\mathrm{R}$ \\
\hline 16 & $4(2) 1425$ & 3.0 & 2.5 & 0.7 & 84.4 & 7.8 & 0.0 & 7.8 & 28 & -6 & -1 & $\mathrm{R}$ \\
\hline 17 & $98 / 2226$ & 3.2 & 3.0 & 1.0 & 91.3 & 7.5 & 0.0 & 7.5 & 27 & -5 & -0.8 & MR \\
\hline 18 & $96 / 1569$ & 3.3 & 3.1 & 1.1 & 94.1 & 9.1 & 0.0 & 9.1 & 26 & -4 & -0.6 & MR \\
\hline 19 & 30572 & 3.4 & 6.9 & 1.0 & 201.4 & 46.2 & 0.0 & 46.2 & 25 & -3 & -0.4 & MR \\
\hline 20 & $96 / 0603$ & 3.4 & 3.4 & 1.5 & 99.3 & 8.7 & 0.0 & 8.7 & 24 & -2 & -0.4 & MR \\
\hline 21 & M98/0068 & 3.8 & 3.3 & 1.2 & 86.4 & 10.3 & 0.0 & 10.3 & 23 & -1 & -0.2 & MR \\
\hline 22 & M98/0028 & 3.9 & 6.4 & 2.4 & 165.7 & 17.5 & 0.0 & 17.5 & 22 & 0 & 0 & MR \\
\hline 23 & $96 / 1632$ & 4.0 & 3.6 & 1.3 & 91.0 & 8.9 & 0.0 & 8.9 & 21 & 1 & 0.2 & MS \\
\hline 24 & $97 / 0162$ & 4.1 & 4.0 & 1.6 & 96.5 & 10.0 & 0.0 & 10.0 & 20 & 2 & 0.4 & MS \\
\hline 25 & $98 / 0581$ & 4.3 & 6.2 & 2.2 & 145.5 & 18.2 & 0.0 & 18.2 & 19 & 3 & 0.4 & MS \\
\hline 26 & $98 / 2101$ & 4.3 & 5.4 & 1.9 & 126.7 & 14.9 & 0.0 & 14.9 & 18 & 4 & 0.6 & MS \\
\hline 27 & $99 / 2123$ & 4.7 & 4.9 & 1.7 & 103.7 & 13.8 & 0.0 & 13.8 & 17 & 5 & 0.8 & MS \\
\hline 28 & $82 / 00058$ & 4.8 & 3.0 & 0.7 & 62.7 & 10.5 & 0.0 & 10.5 & 16 & 6 & 1 & MS \\
\hline 29 & $98 / 0002$ & 5.2 & 4.0 & 1.4 & 75.4 & 13.2 & 0.0 & 13.2 & 15 & 7 & 1.2 & $S$ \\
\hline 30 & $97 / 0211$ & 6.3 & 2.6 & 1.0 & 40.7 & 7.5 & 1.9 & 9.4 & 14 & 8 & 1.2 & $S$ \\
\hline 31 & $98 / 0510$ & 6.4 & 11.5 & 4.1 & 179.3 & 34.4 & 0.0 & 34.4 & 13 & 9 & 1.4 & $S$ \\
\hline 32 & $95 / 0166$ & 6.5 & 4.9 & 2.0 & 76.1 & 13.6 & 0.0 & 13.6 & 12 & 10 & 1.6 & $S$ \\
\hline 33 & $96 / 1642$ & 7.3 & 2.8 & 1.4 & 38.7 & 6.5 & 4.0 & 10.5 & 11 & 11 & 1.8 & $S$ \\
\hline 34 & M98/0040 & 7.5 & 5.9 & 2.2 & 79.3 & 15.4 & 3.1 & 18.5 & 10 & 12 & 2 & $S$ \\
\hline 35 & $92 / 0326$ & 7.9 & 4.3 & 1.7 & 54.3 & 11.1 & 3.6 & 14.7 & 9 & 13 & 2 & $S$ \\
\hline 36 & $96 / 0523$ & 8.3 & 7.9 & 2.8 & 95.1 & 20.0 & 0.0 & 20.0 & 8 & 14 & 2.2 & HS \\
\hline 37 & $92 \mathrm{~B} / 00061$ & 9.3 & 10.1 & 4.1 & 109.1 & 28.6 & 0.0 & 28.6 & 7 & 15 & 2.4 & $\mathrm{HS}$ \\
\hline 38 & $92 \mathrm{~B} / 00068$ & 13.4 & 13.9 & 5.3 & 103.8 & 37.2 & 0.0 & 37.2 & 6 & 16 & 2.6 & HS \\
\hline 39 & $98 / 0505$ & 14.3 & 9.0 & 3.4 & 63.1 & 24.4 & 5.6 & 30.0 & 5 & 17 & 2.8 & HS \\
\hline 40 & $92 / 0325$ & 15.9 & 9.9 & 3.7 & 62.4 & 23.8 & 7.4 & 31.3 & 4 & 18 & 2.8 & HS \\
\hline 41 & $99 / 6012$ & 17.5 & 32.8 & 12.4 & 187.8 & 89.4 & 1.5 & 90.9 & 3 & 19 & 3 & VHS \\
\hline 42 & $94 / 0026$ & 19.1 & 15.8 & 6.5 & 82.9 & 43.0 & 4.9 & 47.8 & 2 & 20 & 3.2 & VHS \\
\hline \multirow[t]{3}{*}{43} & $92 / 0067$ & 21.2 & 29.5 & 12.0 & 139.4 & 80.0 & 0.0 & 80.0 & 1 & 21 & 3.4 & VHS \\
\hline & Overall & 5.4 & 9.0 & 0.5 & 168.4 & 90.9 & 0.0 & 90.9 & Gn & SD & & \\
\hline & Grand mean & 5.7 & 5.1 & 0.8 & 88.4 & 20 & 1.2 & 21.2 & 22 & 12.6 & & \\
\hline
\end{tabular}

$\dagger \mathrm{Xn}$, rank, is based on mean rot in descending order; $\mathrm{Gn}$, grand mean of rank; D, deviation=Xn-Gn; SD, standard deviation of rank; stdmean, standardized mean=D/SD; $x$, not applicable; class: VHR, very highly resistant; HR, highly resistant; R, resistant; MR, moderately res istant; MS, moderately susceptible; S, susceptible; HS, highly susceptible; VHS, very highly susceptible. 


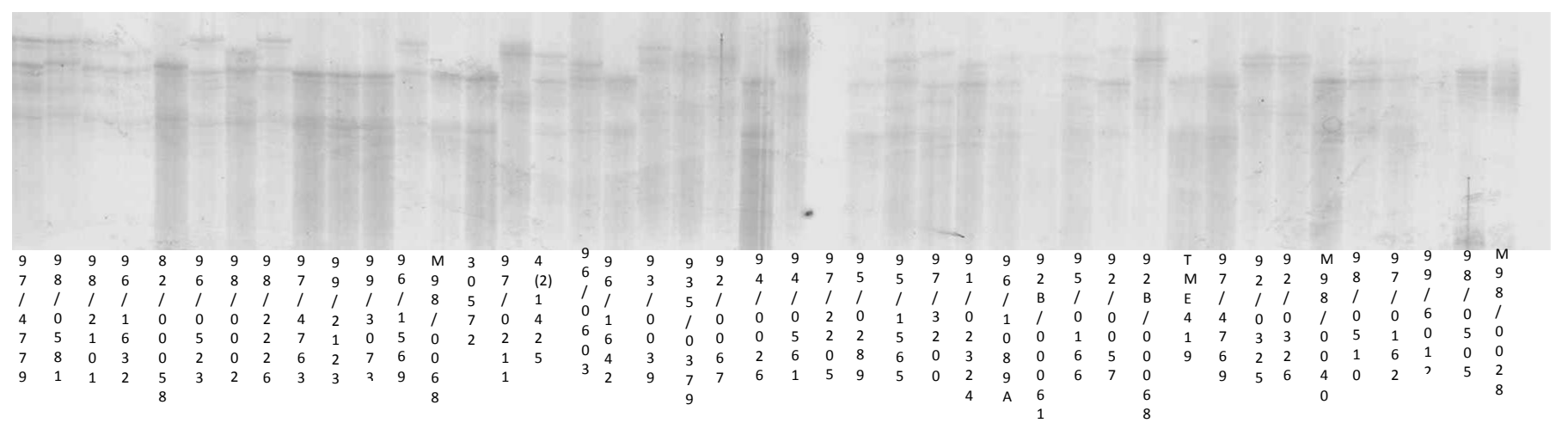

Figure 2. The genotyping profile pattern of 43 CMD-resistant genotypes of cassava by SSRY101 using $6 \%$ polyacrylamide gel electrophoresis and silver staining method.

Table 2. Estimates of genetic F-statistics, heterozygosity over population and genetic differentiation among the eight classes of root rot resistance generated within $43 \mathrm{CMD}$-resistant genotypes of cassava

\begin{tabular}{|c|c|c|c|c|c|c|c|c|}
\hline Rot class & VHR & HR & $\mathbf{R}$ & MR & MS & $\mathbf{s}$ & HS & VHS \\
\hline \multicolumn{9}{|c|}{ F-Statistics } \\
\hline$N$ & 3 & 7 & 6 & 6 & 6 & 7 & 5 & 3 \\
\hline Ă & 3.556 & 4.611 & 4.389 & 4.222 & 4.611 & 4.778 & 4.5 & 3.111 \\
\hline $\mathrm{P} \%$ & 100 & 100 & 100 & 100 & 100 & 100 & 100 & 94.4 \\
\hline$A R$ & 1.787 & 1.758 & 1.789 & 1.795 & 1.776 & 1.793 & 1.739 & 1.763 \\
\hline$\hat{\mathrm{H}}_{\mathrm{e}}$ & 0.759 & 0.745 & 0.771 & 0.781 & 0.764 & 0.780 & 0.724 & 0.701 \\
\hline \multirow[t]{3}{*}{$\mathrm{F}_{\mathrm{ST}}$} & -0.171 & -0.243 & -0.196 & -0.167 & -0.186 & -0.163 & -0.271 & -0.287 \\
\hline & \multicolumn{8}{|c|}{ Heterozygosity over population } \\
\hline & $\mathrm{H}_{\mathrm{O}}$ & $\mathrm{H}_{\mathrm{T}}$ & $\mathrm{H}_{\mathrm{S}}$ & $D_{S T}$ & $\mathrm{G}_{\mathrm{ST}}$ & $\mathrm{F}_{\mathrm{ST}}$ & & \\
\hline Mean & 0.911 & 0.764 & 0.755 & 0.009 & 0.011 & 0.011 & & \\
\hline SD & 0.116 & 0.043 & 0.035 & 0.027 & 0.034 & 0.033 & & \\
\hline \multirow[t]{2}{*}{ SE \pm} & 0.027 & 0.010 & 0.008 & 0.006 & 0.008 & 0.008 & & \\
\hline & \multicolumn{8}{|c|}{ Genetic differentiation pairwise matrix based on $\mathrm{F}_{\mathrm{ST}}$, theta, estimator } \\
\hline VHR & 0 & 0.0331 & -0.0103 & 0.0232 & 0.0424 & 0.0031 & 0.0047 & 0.0316 \\
\hline $\mathrm{HR}$ & & 0 & -0.0034 & 0.0004 & 0.0112 & -0.0174 & 0.0187 & 0.0523 \\
\hline $\mathrm{R}$ & & & 0 & 0.0012 & 0.0214 & -0.0178 & 0.0158 & 0.0256 \\
\hline MR & & & & 0 & -0.0134 & -0.0132 & 0.0145 & 0.0445 \\
\hline MS & & & & & 0 & -0.0009 & 0.0424 & 0.0377 \\
\hline S & & & & & & 0 & -0.0058 & 0.0147 \\
\hline HS & & & & & & & 0 & 0.0235 \\
\hline VHS & & & & & & & & 0 \\
\hline & Mean & Min. & Max & SD & SE \pm & & & \\
\hline & 0.1186 & -0.0187 & 0.0523 & 0.0194 & 0.0024 & & & \\
\hline
\end{tabular}

$\mathrm{N}$, sample size; Ă. mean number of alleles; P\%, percentage of polymorphic loci; AR, mean allelic richness; $\hat{H}_{\mathrm{e}}$, mean gene diversity; $\mathrm{H}_{\mathrm{O}}$, observed heterozygosity; $\mathrm{H}_{\mathrm{S}}$, within class heterozygosity; $\mathrm{H}_{\mathrm{T}}\left(\mathrm{H}_{\mathrm{S}}+\mathrm{D}_{\mathrm{ST}}\right)$, total heterozygosity; $\mathrm{D}_{\mathrm{ST}}$, between class heterozygosity; $\mathrm{G}_{\mathrm{ST}}\left(\mathrm{D}_{\mathrm{ST}} / \mathrm{H}_{\mathrm{T}}\right)$, proportion of between class heterozygosity; and $F_{S T}$, (theta) fixation index for genetic differentiation; VHR, very highly resistant; HR, highly resistant; R, resistant; MR, moderately resistant; MS, moderately susceptible; S, susceptible; HS, highly susceptible; and VHS, very highly susceptible.

that ranged from 3.111 for VHS to 4.778 for $\mathrm{S}$ with a mean of 4.222; ÂR, 1.739 for HS to 1.795 for MR with an average of $1.775 ; \mathrm{P} \%$ was $100 \%$ for each class except for VHS that had $94.4 \%$, with a mean of $99.3 \%$. Nei's estimation of genetic diversities for class revealed $\hat{\mathrm{H} e}$ of
0.701 for VHS to 0.781 for MR and S on a mean of 0.754 , and heterozygosity estimators over population were mean $\mathrm{H}_{\mathrm{S}}$ of 0.755 ; between class $\mathrm{D}_{\mathrm{ST}}$ of 0.009 , which contributed a $\mathrm{G}_{\mathrm{ST}}$ of 0.012 ; a $\mathrm{H}_{\mathrm{T}}$ of 0.764 ; and $\mathrm{H}_{\mathrm{O}}$ of 0.911 (Table 2). A total of 3 private alleles were detected 
from 3 loci within 3 classes, allele 3, from SSRY12 for VHR class; 3, SSRY101 for HS; and also 3, SSRY177 for R. Genetic differentiation $\left(F_{S T}\right)$ distance by Weir and Cockerham (1984) estimation between pairs of rot class ranged from -0.0178 between $R$ and $S$ to 0.0523 for VHR and HR with a mean of 0.0119 . NTSYS generated 7 clusters among the 8 classes of rot with HR and VHS in the same group (Figure 3).

The F-statistics for 18 SSR loci had Â that ranged from 4 for SSRY182 to 7 for SSRY69 and 164 with an average of 5.63; AR ranged from 1.701 for SSRY175 to 1.817 for SSRY108 with a mean of 1.764; and $\hat{\mathrm{H} e}$ ranged from 0.681 for SSRY49 to 0.835 for SSRY164. For genetic diversity estimators, $\mathrm{H}_{\mathrm{O}}$ ranged from 0.699 for SSRY4 and 175 to 1.000 for SSRY5, 45, 52, 61, and NS158 with a mean of $0.910 ; \mathrm{H}_{\mathrm{T}}, 0.700$ for SSRY175 to 0.818 for SSRY164 with a mean of $0.764 ; \mathrm{H}_{\mathrm{S}}$ within rot class ranged from 0.680 for SSRY49 to 0.830 for SSRY164, an average of 0.755 ; and $D_{S T}$ between class ranged from 0.008 for SSRY79 to 0.083 for SSRY64 with a mean of 0.009 ; and contributed a proportion of $\mathrm{G}_{\mathrm{ST}}$ that ranged from -0.001 for SSRY69 to 0.104 for SSRY64 on an average of 0.012 . Genetic differentiation estimator, $F_{S T}$ (theta) over allele ranged from -0.103 for allele 5 SSRY12 to 0.255 for allele 3 SSRY49; over locus ranged from 0.034 for SSRY12 to 0.092 for SSRY49 with an overall mean of 0.011; and using jackknifing method, over locus was $(-0.033 \pm 0.013)$ for SSRY12 to $0.098 \pm 0.064$ for SSRY49 with an overall mean of $0.011 \pm 0.008$ (Table 3 ).

DARwin analysis based on Jaccard-weightedneighbour-joining gave a dissimilarity matrix with a coefficient that ranged from 0.18 to 0.81 with a mean of 0.60 and generated a tree that revealed 4 main clusters with sub-clusters that made up a total of 10 clusters of HZG. The first HZG (HZG1) consisted of 4 genotypes (2 VHR and $2 \mathrm{R}$ ); HZG2 also had 4 (1 HR, $2 \mathrm{R}$ and $1 \mathrm{~S}$ ); HZG3, 4, with one genotype each in HR, MR, MS, and S classes; HZG4 had 2 that belong to MS class, only; HZG5, 3, $2 \mathrm{MR}$ and $1 \mathrm{~S}$; HZG6, 5, $2 \mathrm{HR}, 1 \mathrm{MR}$, and 2 MS; HZG7, 3, $1 \mathrm{HR}, 1 \mathrm{R}$, and $1 \mathrm{HS}$; HZG8, 6, $2 \mathrm{HR}, 1$ $\mathrm{MR}, 1 \mathrm{~S}$ and $2 \mathrm{HS}$; HZG9, 5, $1 \mathrm{VHR}, 1 \mathrm{R}, 1 \mathrm{MR}$, and $2 \mathrm{~S}$; and HZG10, 7, $1 \mathrm{MS}, 1 \mathrm{~S}, 2 \mathrm{HS}$, and 3 VHS. Some groupings were unique for a few classes such as HZG4 for MS class, HZG1 and HZG2 for genotypes with a good level of resistance (but an outlier $S$ in $H Z G$ 2), and HZG10 for those with a high level of susceptibility with an odd MS (Figure 4).

\section{DISCUSSION}

\section{Variations of root rot within the cassava collection}

Large variations of root rot disease have been previously detected in cassava collections, and there has been lots of documented work on the pathogens and their characterization. Onyeka et al. (2006) observed a large variation of rot response and severity among improved varieties and landraces, and so also was Okechukwu et al. (2009) among improved varieties of cassava. The present study was also able to detect a large variation of root rot severity using the percentage estimate of rotten roots to total roots harvested at 12 MAP. Rank-sum grouping identified TMS 96/1089A (mean rot of $1.2 \%$ ) as the best genotype for root rot resistance among the 43 genotypes of cassava assessed. The min. mean rot value of $1.2 \%$ obtained in this study is much lower than that by Okechukwu et al. (2009) of $7.58 \%$ for TMS $97 / 2205$ but higher than that of Aigbe and Remison (2010) of $0.00 \%$ for TMS 4(2)1425. The best genotype in the present study was not assessed by Aigbe and Remison (2010) but by Okechukwu et al. (2009) and it took 4th position with mean rot of $11.42 \%$ and belongs to $R$ class of the six classes. This genotype recorded a $0.00 \%$ rot in 8 out of 25 zones as reported by Okechukwu et al. (2009) across Nigeria. The best genotype for rot resistances by Okechukwu et al. (2009) and Aigbe and Remison (2010) had mean rot of $2.29(\mathrm{HR})$ and $2.90 \%(\mathrm{R})$, respectively, in our present study. The differences observed in these values is mainly the result of differences in the number of location(s), which are highly influenced by $G \times E$ interactions, as explained by Egesi et al. (2007) for yield parameters and diseases in cassava breeding. Therefore, TMS 96/1089A is identified as the best for root rot resistance followed by $97 / 4779$ and 94/0561 in agroecozones similar to the environment of IITA-Ibadan assessed in the present study and this finding is subject to further exploration. The first ten best genotypes in Table 1 are recommended for farmers around the agroecozones of IITA, Ibadan for increased productivity.

\section{Gene diversity and identification of putative hybridizing parents using SSR markers}

SSR markers have been used extensively for genetic diversity studies in cassava, either for genotypic identification or establishing genetic relationships and differentiation as a prerequisite to its molecular breeding improvement (Mba et al., 2001; Moyib et al., 2007; Siqueira et al., 2009). Each time, SSR markers were able to provide useful information that is employable for breeding objectives. In the present study, SSR markers were used for genetic diversity and the identification of putative hybridizing parents for root rot resistance. Each of the 18 SSR markers used showed P\% of within each class except SSRY182 for the VHS class, which was due to lack of amplified alleles by TMS 94/0026, one of the 3 genotypes in the class. SSR markers detected high $\mathrm{H}_{\mathrm{S}}$ within all the classes of rot with MR and $S$ class having the highest $(0.781)$ and the lowest diversity was observed for VHS $(0.701)$ with a mean of 0.753 . The estimated $\mathrm{H}_{S}$ was observed to depend more on the nature of $\check{A}, \mathrm{P} \%$, ĂR, and $\hat{H}_{e}$ of loci rather than the sample size within 


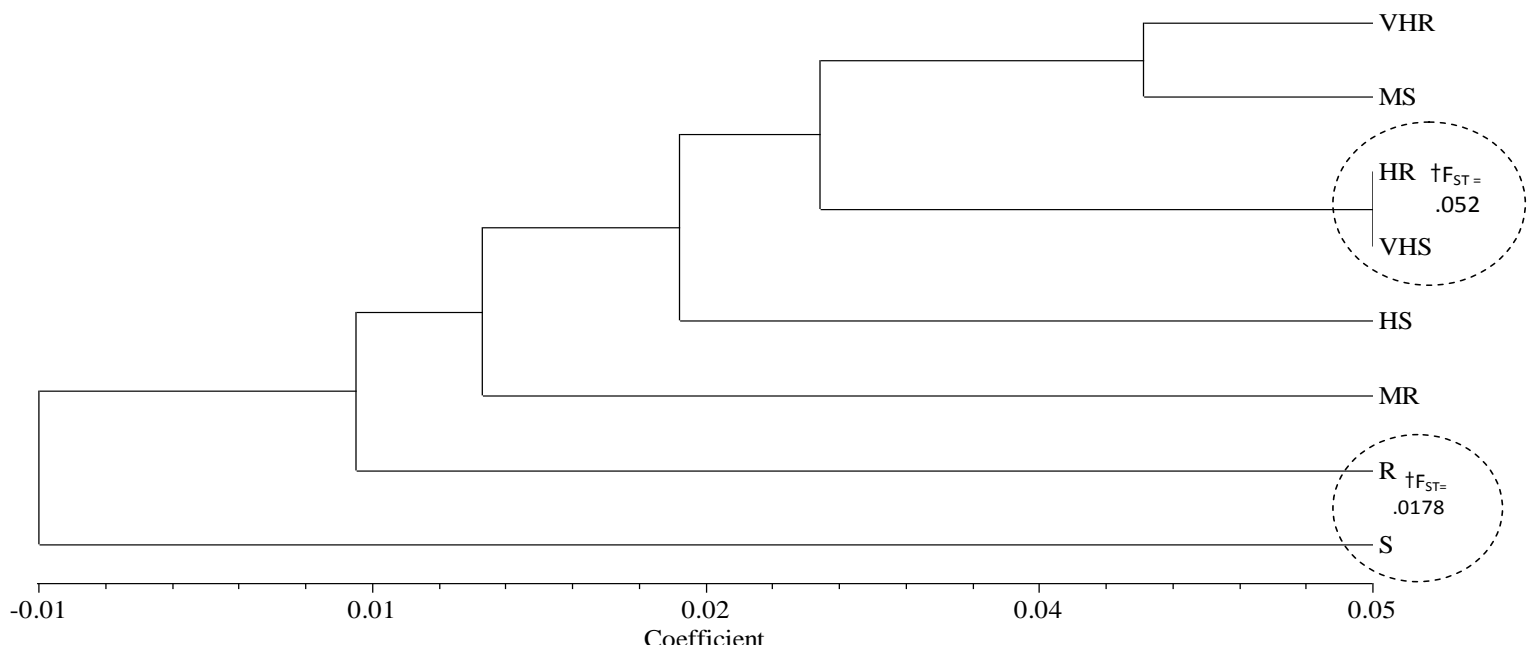

Figure 3. A dendrogram showing genetic differentiation ( $\left.\mathrm{F}_{\mathrm{ST}}\right)$ between pairs of eight classes for root rot resistance among 43 CMD-resistant genotypes of cassava based on 18 SSR loci using unweighted pair-grouping method of arithmetic in NTSYS software analysis package. VHR, very highly resistant class; HS, highly susceptible; MR, moderately resistant; MS, moderately susceptible; R, resistant; S, susceptible class; VHR, very highly resistant; and VHS, very highly susceptible. Highest estimated genetic differentiation was between VHS and HR with a value of 0.052 , while the least differentiation was between $\mathrm{R}$ and $\mathrm{S},-0.0178$.

Table 3. The locus name, locus map location in cassava genome and Nei's estimation of heterozygosity of the 18 SSR markers used for gene diversity analysis of root rot resistance among 43 CMD-resistant genotypes of cassava.

\begin{tabular}{|c|c|c|c|c|c|c|c|c|c|c|}
\hline \multirow{2}{*}{ Locus } & \multirow{2}{*}{$\begin{array}{l}\text { Map } \\
\text { location† }\end{array}$} & \multirow{2}{*}{ Â } & \multirow{2}{*}{ AR } & \multicolumn{7}{|c|}{ Nei's estimation of heterozygosity } \\
\hline & & & & $\mathrm{H}_{\mathrm{e}}$ & $\mathrm{H}_{\mathrm{O}}$ & $\mathrm{H}_{\mathrm{S}}$ & $\mathbf{H}_{\mathrm{T}}$ & $\mathrm{D}_{\mathrm{ST}}$ & $\mathrm{G}_{\mathrm{ST}}$ & $\mathbf{F}_{\mathrm{ST}}$ \\
\hline SSRY12 & $\mathrm{H}$ & 6 & 1.729 & 0.745 & 0.957 & 0.748 & 0.725 & -0.023 & -0.031 & -0.033 \\
\hline SSRY61 & nd & 5 & 1.756 & 0.752 & 1 & 0.753 & 0.75 & -0.003 & -0.004 & 0.002 \\
\hline SSRY52 & $\mathrm{H}$ & 5 & 1.736 & 0.732 & 1 & 0.732 & 0.741 & 0.009 & 0.012 & 0.007 \\
\hline SSRY182 & UMA & 4 & 1.754 & 0.719 & 0.958 & 0.723 & 0.746 & 0.023 & 0.03 & -0.021 \\
\hline SSRY175 & $\mathrm{K}$ & 5 & 1.701 & 0.712 & 0.699 & 0.707 & 0.7 & -0.007 & -0.009 & -0.014 \\
\hline SSRY79 & nd & 5 & 1.747 & 0.756 & 0.858 & 0.754 & 0.746 & -0.008 & -0.01 & -0.011 \\
\hline SSRY5 & $J$ & 5 & 1.798 & 0.823 & 1 & 0.82 & 0.8 & -0.02 & -0.024 & -0.02 \\
\hline SSRY101 & $J$ & 6 & 1.741 & 0.724 & 0.961 & 0.735 & 0.733 & -0.002 & -0.002 & -0.002 \\
\hline SSRY4 & nd & 6 & 1.725 & 0.696 & 0.699 & 0.697 & 0.728 & 0.031 & 0.043 & 0.033 \\
\hline SSRY49 & $\mathrm{K}$ & 5 & 1.743 & 0.681 & 0.979 & 0.68 & 0.73 & 0.05 & 0.068 & 0.098 \\
\hline SSRY164 & $\mathrm{H}$ & 7 & 1.807 & 0.835 & 0.719 & 0.83 & 0.818 & -0.011 & -0.014 & -0.014 \\
\hline SSRY69 & $\mathrm{D}$ & 7 & 1.782 & 0.788 & 0.914 & 0.787 & 0.786 & -0.001 & -0.001 & 0.004 \\
\hline SSRY45 & nd & 6 & 1.787 & 0.771 & 1 & 0.772 & 0.783 & 0.012 & 0.015 & 0.016 \\
\hline SSRY171 & C & 6 & 1.809 & 0.825 & 0.0723 & 0.821 & 0.802 & -0.02 & -0.024 & -0.004 \\
\hline SSRY108 & $D$ & 6 & 1.817 & 0.778 & 0.982 & 0.784 & 0.812 & 0.028 & 0.035 & 0.018 \\
\hline SSRY177 & $U$ & 6 & 1.773 & 0.75 & 0.975 & 0.754 & 0.766 & 0.013 & 0.017 & 0.02 \\
\hline NS-158 & nd & 6 & 1.782 & 0.773 & 1 & 0.775 & 0.782 & 0.007 & 0.009 & -0.001 \\
\hline \multirow[t]{6}{*}{ SSRY64 } & nd & 6 & 1.776 & 0.699 & 0.958 & 0.711 & 0.794 & 0.083 & 0.104 & 0.073 \\
\hline & Mean & 5.7 & 1.764 & 0.753 & 0.91 & 0.755 & 0.763 & 0.009 & 0.012 & 0.011 \\
\hline & Min. & 4 & 1.701 & 0.681 & 0.699 & 0.68 & 0.7 & -0.023 & -0.031 & -0.033 \\
\hline & Max. & 7 & 1.817 & 0.835 & 1 & 0.83 & 0.818 & 0.083 & 0.104 & 0.098 \\
\hline & SD & 0.767 & 0.033 & 0.045 & 0.116 & 0.043 & 0.035 & 0.027 & 0.034 & 0.033 \\
\hline & $\mathrm{SE} \pm$ & 0.181 & 0.008 & 0.011 & 0.027 & 0.01 & 0.008 & 0.006 & 0.008 & 0.008 \\
\hline
\end{tabular}

†Source: Mba et al., 2001. Â, the mean number of alleles; AR, allelic richness; $\mathrm{H}_{\mathrm{O}}=$ observed heterozygosity; $\hat{H}_{\mathrm{e}}$, gene diversity; $\mathrm{H}_{\mathrm{S}}=$ within class heterozygosity; $\mathrm{H}_{\mathrm{T}}$, total hetrozygosity; $\mathrm{D}_{\mathrm{ST}}=$ among class heterozygosity; $\mathrm{G}_{\mathrm{ST}}$, proportion of among class diversity $\left(\mathrm{G}_{\mathrm{ST}}=\mathrm{D}_{\mathrm{ST}} / \mathrm{HT}\right)$; $\mathrm{FST}$, fixation index estimator for genetic differentiation; nd, no linkage data. 


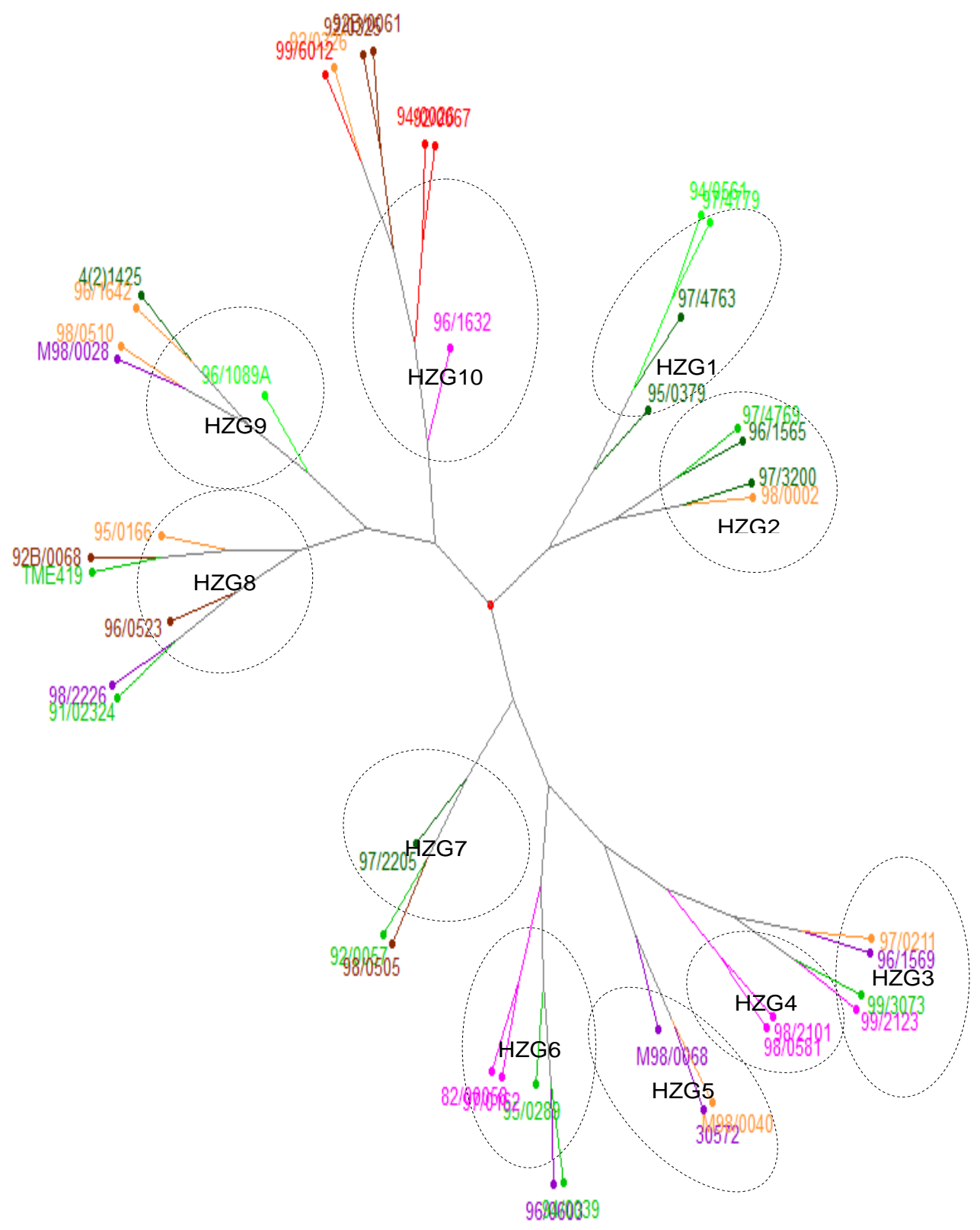

Figure 4. A phylogenetic tree showing putative hybridizing groups for root rot resistance among 43 CMD-resistant genotypes of cassava using 18 SSR markers based on weighted neighborjoining Jaccard dissimilarity index in DARwin software package. Red, VHS genotypes; deep brown, HS; brown, S; lilac, MS; purple, MR; deep green, R; green, HR and lemon green, VHR; HZG, hybridizing group; VHR, very highly resistant; HR, highly resistant; R, Resistant; MR, moderately resistant; S, susceptible; HS, highly susceptible; VHS, very highly susceptible. Ten putative HZGs were identified among the 43 genotypes of cassava. There is a mixed of more than two rot classes in a HZG except HZG1, 4, and 5.

classes. The mean value of $\hat{H e}, 0.754$, obtained in the present study is higher than the mean value of 0.57 obtained for collections in regions of Brazil (Siqueira et al., 2009); 0.477 for African landraces (Lokko et al., 2006); and 0.535 for African and Neotropical countries (Fregene et al., 2003). This higher diversity obtained in the present study may be attributed to the diverse exotic sources of the 43 improved genotypes. Other studies assessed landraces that may be representative of local farmers' accessions. Furthermore, the study revealed that cassava still maintains high genetic diversity which favors production of large number of new varieties that will be resistant to prevalent biotic and abiotic stresses in targeted areas. 
According to Nei's estimation, the SSR markers revealed a high observed heterozygosity $\left(\mathrm{H}_{\mathrm{O}}=0.911\right)$ and total heterozygosity $\left(\mathrm{H}_{T}=0.764\right)$ among the genotypes used for the study. The high estimated $\mathrm{H}_{T}$ was largely contributed by the diversity within the rot class $\left(\mathrm{H}_{\mathrm{S}}\right.$ $=0.755$ ), while a small proportion was due to diversity between classes (mean $\mathrm{G}_{\mathrm{ST}}, \mathrm{D}_{\mathrm{ST}} / \mathrm{H}_{\mathrm{T}}=0.012$ ). The percentage proportion of $\mathrm{G}_{\mathrm{ST}}(12 \%)$ obtained in the present study is higher than the $10 \%$ obtained by Fregene et al. (2003) but lower than $13 \%$ by Siqueira et al. (2009). All these values are lower than expected for predominantly out-crossing crops such as cassava, according to Hamrick and Godt (1997). The average genetic differentiation, $F_{S T}(0.011)$ based on Jackknifing was low and similar to the estimated $\mathrm{G}_{\mathrm{ST}}, 0.012$, between class, which took into account variation in sample size. The lowest pairwise $F_{S T}$ differentiation $(-0.0178)$ was found between $S$ and $R$, while the highest $(0.0523)$ was between VHS and HR. These values were lower than the min. (0.0076) and max. (0.2696) average $F_{S T}$ among regions (mean $=0.079$ ) by Fregene et al. (2003). The authors indicated that their maximum value was odd but expected to be higher than the present study because of the larger number of genotypes and regions they assessed. Furthermore, the lower differentiation obtained in the present study is expected because of exchange of cassava across regions and more importantly, the particular collection assessed for this study was bred for common goal (resistance to CMD).

The 18 SSR markers used were able to identify 10 HZGs among the 43 genotypes of cassava in the present study. The observed clusters were not representatives of the rot classes; therefore, each HZG is composed of genotypes that are closely related genetically and not morphologically, which would facilitate hybridization and transfer of genes among the genotypes within a cluster.

This further explains why many HZGs were having genotypes from very different classes of root rot but a few were distinct for some related classes, such as HZG1 for VHR, HR, and R; HZG10 for VHS, HS, and MS. This observed distinction might be partly caused by some of the private alleles that were unique such as allele 3 from SSRY 12 for VHR, 177 for HR and 101 for HS. However, no private allele was distinct for VHS despite the fact that all the 3 genotypes were found clustered together in HZG10. Also, none was found for MS in HZG4, though they were also found in other HZGs. The clustering of the 3 VHS genotypes in the same HZG is fully supported by the lowest heterozygosity of 0.701 observed for the class. The results indicated that there are much more contributing factors than the identified private alleles for the observed clustering in the HZG1 and HZG10, which may have nothing to do with the root rot trait. Moreover, SSR are random markers and therefore, they do not possess a strong phenotypic variability relationship with agronomic traits (Dwivedi et al., 2007), which necessitate the need for new and large number of functional tools for genetic analysis in cassava.

More impotantly, SSR markers generated groupings among the genotypes for root rot resistance, which would facilitate generation of large numbers of new varieties that could be resistant to diseases and pests prevalent in targeted regions among the improved genotypes assessed. The estimated low $\mathrm{G}_{\mathrm{ST}}$ and $\mathrm{F}_{\mathrm{ST}}$ between the classes would also facilitate crosses among the genotypes in the different classes of rot resistance and it is also useful for easy introgression of useful genes among them. Therefore, SSRs still remain important markers for routine evaluation of genetic diversity such as estimation of genetic variation, genotypic groupings and identification, development of core germplasm, and elimination of duplicates or domants within cassava collections and population. The findings of the present study are therefore useful for improved breeding programs for root rot resistance in cassava.

Abbreviations: A, Number of alleles; $\mathbf{A}$, mean number of allele; AR, allelic richness; CMD, cassava mosaic disease; DARwin, dis-similarity analysis representatives for windows; $\mathbf{D}_{\mathrm{ST}}$, between class heterozygosity; Freq., frequency; FSTAT, F-statistics; $\mathbf{F}_{\mathbf{S T}}$, (theta) fixation index, estimator for genetic differentiation; $\mathbf{G}_{\mathrm{ST}}$, proportion of heterozygosity between class; He, heterozygosity; He, expected heterozydosity; $\mathbf{H}_{\mathrm{o}}$, observed heterozygosity; $\mathbf{H}_{\mathrm{S}}$, within class heterozygosity; $\mathbf{H}_{\mathrm{T}}$, total heterozygosity; HS, highly susceptible; HZG, hybridizing group; IITA, international institute of tropical agriculture; MR, moderately resistant; $\mathbf{M S}$, moderately susceptible; $\mathbf{N R}_{\mathbf{t}} \mathbf{R}$, number of rotten roots; NTSYS, numeric taxanomy system of statistics; P, polymorphic loci; R, resistant; Rootrot, root rot; S, susceptible; SAS, statistical analysis system; SSR, simple sequence repeat; Stdzdmean, standardized mean; TNR, total number of roots harvested; VHR, very highly resistant; VHS, very highly susceptible.

\section{REFERENCES}

Aigbe SO, Remison SU (2010). The influence of root rot on starch content of cassava planted in different ecological environment of Nigeria. Nig. Annal. Nat. Sci. 10(1):60-70.

Dellaporta SL, Wood J, Hicks JB (1983). A plant DNA mini-preparation: Version II. Plant Mol. Biol. Rep. 1:19-21.

Dwivedi SL, Crouch JH, Mackill DJ, Xu Y, Blair MW, Ragot M, Upadhyaya HD, Ortiz R (2007). The Molecularization of public sector crop breeding: Progress, problems, and prospects. Adv. Agron. 95:163-318.

Egesi CN, Ilona P, Aigbe FO, Akoroda MO, Dixon AGO (2007). Genetic variation and GXE interaction for yield and other agronomic traits in cassava in Nigeria. Agron. J. 99:1137-1142.

FAO (1995). Food and Agriculture Organization.Production and trade yearbook, 1995. FAO, Rome,

FAO (2006). Food and Agriculture Organization. Food Outlook: Global market Analysis. http//www.fao.org//.

Fregene MA, Suarez M, Mkumbira J, Kulembeka H, Ndedya E, Kulaya A, Mitchel S, Gullberg U, Rosling H, Dixon AGO, Dean R, Kresovich $S$ (2003). Simple sequence repeat marker diversity in cassava 
andraces: genetic diversity and differentiation in an asexually propagated crop. Theor. Appl. Genet. 107:1083-1093.

Fregene M, Puonti-Kearlas J (2005). Cassava biotechnology. In Hillocks RJ, Thresh JM, Bellotti AC (Eds) Cassava: Biology, production and utilization. CABI International, UK.

Goudet J (2002). FSTAT (version. 2.9.3.2.) A computer software to calculate F-statistics in genetics studies J. Hered 86:485-486.

Hamrick H, Godt MJW (1997). Allozyme diversity in cultivated crop. Crop Sci. 37:26-30.

Lokko Y, Dixon A, Offei S, Danquah E, Fregene M (2006). Assessment of genetic diversity among African cassava (Manihot esculenta Crantz) accession resistant to the cassava mosaic disease using SSR markers. Genet. Resour. Crop Evol. 53:1441-1453.

Mba REC, Stephenson P, Edwards K, Melzer S, Nkumbira J, Gullberg U, Apel K, Gale M, Tohme J, Fregene M (2001). Simple sequence repeat (SSR) markers survey of the cassava (Manihot esculenta Crantz) genome: Towards an SSR-based molecular genetic map of cassava. Theor. Appl. Genet. 102:21-31.

Moses E, Asafu-Agyei JN, Ayueboteng F (2005). Identification and control of root rot diseases of cassava: Disease guide. First year report of International Society for Plant Pathology (ISSP) Congress Challenge on the development of appropriate strategies to control cassava diseases in Ghana. http://www.isppweb.org/foodsecurity_cassavaghana.asp. accessed 13 Jan. 2011.

Moyib OK, Odunola OA, Dixon AGO (2007). SSR markers revealed genetic variation between improved cassava cultivars and commonly grown Nigerian landraces within a collection of Nigerian cassava germplasm. Afr. J. Biotechnol. 6(23):2666-2674.

Mskita W, James B, Ahounou M, Baimey H, Facho BG, Fagbemisi R (1998). Discoveries of new diseases of cassava in West Africa. Trop. Agric. 75:58-63.

Mskita W, Bissang B, James BD, Baimey H, Wilkinson HT, Ahounou M, Fagbemisi $R$ (2005). Prevalence and severity of Nattrassia mangiferae root and stem rot pathogen of cassava in Benin. Plant Dis. 89:12-16.

Nei M (1978). Estimation of average heterozygosity and genetic distances from a small number of individuals. Genetics 89:583-590.

Okechukwu RU, Dixon AGO, Akoroda MO, Mwangi M, Bandropadhyay R (2009). Root rot resistance in new cassava varieties introduced to farmers in Nigeria. Exp. Agric. 45:15-24.
Okogbenin E, Marin J, Fregene M (2006). An SSR-Based molecular genetic map of cassava. Euphytica 147(3):433-440.

Onyeka TJ, Dixon AGO, Ekpo EJA (2006). Identification of levels of resistance to cassava root rot disease (Botryodiplodia theobromae) in African landraces and improved germplasm using in vitro inoculation method. Euphytica 145(3):281-288.

Perrier X, Jacquemoud-Collet JP (2006). DARwin software for windows Version 5.0 CIRAD-Agropolis International, Montpellier, France. http://darwin.cirad.fr/darwin/.

Roulph FJ (2000). Numeric Taxonomy and Multivariate Analysis System (NTSYS) for PC Version 2.0j. University of London, UK. Exeter Publishing Ltd. New York, USA.

SAS (2002). Statistical Analysis System for windows Version 9.2. SAS Institute Inc. Cary. NC, USA.

Siqueira MVBM, Queiroz-Silva JR, Bressan EA, Borges A, Perreira KJC, Pinto JG, Veasey EA (2009). Genetic characterization of cassava (Manihot esculenta) landraces in Brazil assessed with simple sequence repeats. Genet. Mol. Biol. 32.1. http//www. gmb,scielopub.org//. doi: 10.1590/S1415-47572009005000010. Accessed 24 Aug. 2010.

Tautz D (1989). Hypervariability of simple sequences as a general source for polymorphic DNA markers. Nucleic Acids Res. 17:64636471.

Weir BS, Cockerham CC (1984). Estimating F-statistics for the analysis of population structure. Evolution 38:1358-1370.

Williams SGK, Kuselik AR, Livak KJ, Rafalski JA, Tiney SV (1990). DNA polymorphisms amplified by arbitrary primers are useful as genetic markers. Nucleic Acids Res. 18:6531-6535. 